\title{
Two Novel HOGA1 Splicing Mutations Identified in a Chinese Patient with Primary Hyperoxaluria Type 3
}

\author{
Xinsheng Wang ${ }^{a}$ Xiangzhong Zhao $^{b}$ Xiaoling Wang ${ }^{c}$ Jian Yao ${ }^{d}$ \\ Feifei Zhang ${ }^{c}$ Yanhua Lang $^{c}$ Sylvie Tuffery-Giraud ${ }^{\mathrm{e}}$ Irene Bottillo $^{f}$ \\ Leping Shao ${ }^{c}$
}

${ }^{a}$ Department of Urology, ${ }^{b}$ Central Laboratory, ${ }^{c}$ Department of Nephrology and d Emergency, Affiliated Hospital, Qingdao University, Qingdao, China; ' ${ }^{\mathrm{L}}$ aboratoire de Génétique de Maladies Rares, Université de Montpellier, Montpellier, France; ${ }^{\mathrm{f} D i v i s i o n}$ of Medical Genetics, Department of Molecular Medicine, Sapienza University, San Camillo-Forlanini Hospital, Rome, Italy

\section{Key Words}

Primary hyperoxaluria type $3 \cdot H O G A 1 \cdot$ Splice mutation .

Mini-gene assay

\section{Abstract}

Background: Twenty-six HOGA1 mutations have been reported in primary hyperoxaluria $(\mathrm{PH})$ type $3(\mathrm{PH} 3)$ patients with c.700 +5G>T accounting for about $50 \%$ of the total alleles. However, $\mathrm{PH} 3$ has never been described in Asians. Methods: A Chinese child with early-onset nephrolithiasis was suspected of having $\mathrm{PH}$. We searched for AGXT, GRHPR and HOGA1 gene mutations in this patient and his parents. All coding regions, including intron-exon boundaries, were analyzed using PCR followed by direct sequence analysis. Results: Two heterozygous mutations not previously described in the literature about HOGA1 were identified (compound heterozygous). One mutation was a successive $2 \mathrm{bp}$ substitution at the last nucleotide of exon 6 and at the first nucleotide of intron 6, respectively (c.834_834 + 1GG>TT), while the other one was a guanine to adenine substitution of the last nucleotide of exon 6 (c.834G>A). Direct sequencing analysis failed to find these mutations in 100 unrelated
(C) 2015 S. Karger AG, Basel

0250-8095/15/0421-0078\$39.50/0 healthy subjects and the functional role on splicing of both variants found in this study was confirmed by a minigene assay based on the pSPL3 exon trapping vector. In addition, we found a SNP in this family (c.715G >A, p.V239l). There were no mutations detected in AGXT and GRHPR. Conclusion: Two novel HOGA1 mutations were identified in association with $\mathrm{PH}$. This is the first description and investigation on mutant gene analysis of PH3 in an Asian.

ㄷ) 2015 S. Karger AG, Basel

\section{Introduction}

Primary hyperoxalurias ( $\mathrm{PHs}$ ) are rare, autosomal recessive, monogenic disorders of glyoxylate metabolism that result in excessive endogenous oxalate synthesis and the formation of calcium oxalate kidney stones [1, 2]. Progressive renal inflammation and interstitial fibrosis from advanced nephrocalcinosis, recurrent urolithiasis and urinary tract infections can cause reduced renal func-

X.W. and X.Z. contributed equally to this article.

\section{KARGER 125}

E-Mail karger@karger.com www.karger.com/ajn 

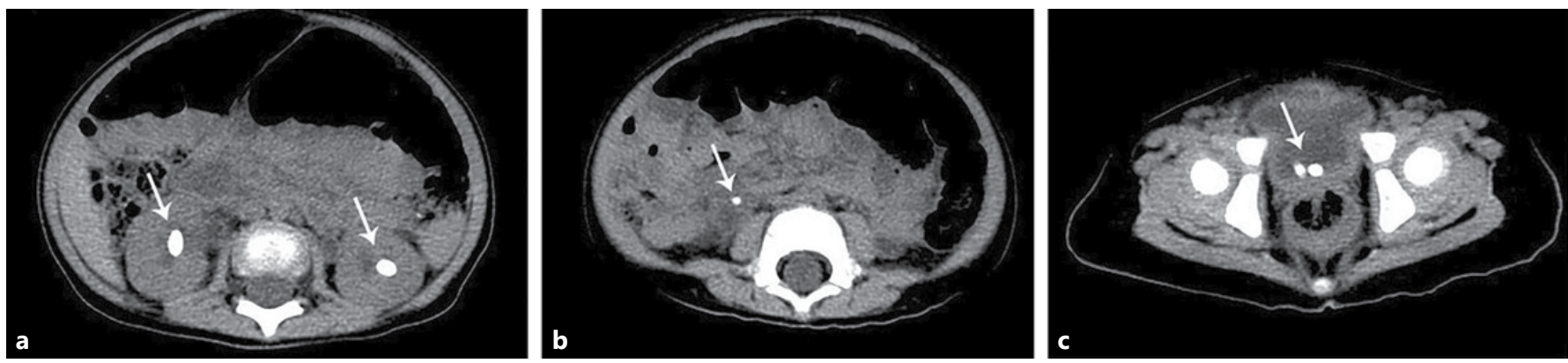

Fig. 1. Abdomen CT of the proband: a bilateral renal calculi; b upper ureteral calculi; c bladder stones.

tion, systemic oxalate deposition and end-stage renal failure with time [3-5].

There are 3 types of PH. PH1 (MIM\# 259900; gene AGXT, MIM\# 604285), the most frequent and most severe $\mathrm{PH}$, results from mutations in peroxisomal alanine: glyoxylate aminotransferase [6-9]. PH2 (MIM\# 260000; gene GRHPR, MIM\# 604296) is caused by deficient glyoxylate reductase/hydroxypyruvate reductase (GR/HPR) enzyme activity [10]. In general, $\mathrm{PH} 2$ shows a less severe phenotype with the absence of infantile oxalosis and ESRD occurring in about $20 \%$ of patients $[11,12]$. $\mathrm{PH}$ type 3 (PH3, MIM\# 613616) is a result of the enzymatic function of loss of 4-hydroxy-2-oxoglutarate aldolase (encoded by HOGA1, MIM\# 613597) [13]. The 4-hydroxy-2-oxoglutarate aldolase is a mitochondrial protein of 327 amino acids $(35 \mathrm{kDa})$. The enzyme, expressed in liver and kidney, catalyzes the final step of mitochondrial hydroxyproline metabolism from 4-hydroxy-2-oxoglutarate to glyoxylate and pyruvate. Mutations in HOGA1 cause the build-up of hydroxy-2-oxoglutarate aldolase, inhibiting GR/HPR function [14]. Compared to $\mathrm{PH} 1$ and $\mathrm{PH} 2, \mathrm{PH} 3$ might be the least severe form, with good preservation of kidney function in most patients. The typical clinical characteristic is early onset of recurrent urolithiasis, but less active stone formation later [11, 12, 15-17]. Both $\mathrm{PH} 2$ and $\mathrm{PH} 3$ may have similar prevalence of about $10 \%$ of total genetically characterized $\mathrm{PH}$ cases [17].

To date, more than 200 mutations have been described in $\mathrm{PH}$ patients, including 26 variants in $\mathrm{PH} 3$ with the 2 most common alleles (c.700 $+5 \mathrm{G}>\mathrm{T}$ and p.E315del) accounting for more than $70 \%$ of the total [15-18]. However, $\mathrm{PH} 3$ patients among Asians have never been reported. In this article, we report a $\mathrm{PH} 3$ case carrying 2 compound heterozygous splicing mutations in HOGA1. The effect of these variants on the splicing process was investigated by minigene assays.

Two Novel Splice Site Mutations in HOGA1

\section{Subjects and Methods}

\section{Case Report}

The proband was a 33-month-old male patient from healthy unrelated parents at full-term normal delivery and with a birth weight of $3.4 \mathrm{~kg}$. His perinatal period was unremarkable. At around 10 months ( 0.8 year) of age, he was admitted to the Nanjing Children's Hospital because of 'slow urination'. Laboratory data showed leukocyte count to be $9.26 \times 10^{9} / 1$, hemoglobin $129 \mathrm{~g} / \mathrm{l}$, blood urea nitrogen $1.89 \mathrm{mmol} / \mathrm{l}$ and SCr $21 \mu \mathrm{mol} / \mathrm{l}$. Blood $\mathrm{pH}$ was $7.39, \mathrm{CO}_{2} \mathrm{CP} 26 \mathrm{mmol} / \mathrm{l}$ and serum electrolyte concentrations including $\mathrm{K}^{+}, \mathrm{Cl}^{-}$and $\mathrm{Ca}^{2+}$ were $5.23,100.6$ and 2.68 $\mathrm{mmol} / \mathrm{l}$, respectively. The concentration of $\mathrm{Ca}^{2+}$ in his urine was $50.5 \mathrm{mg} / \mathrm{l}, \mathrm{Cr} 109 \mathrm{mg} / \mathrm{l}$ and the ratio of urinary calcium/creatinine was $0.46 \mathrm{mg} / \mathrm{mg}$ (normal values: $\leq 0.86 \mathrm{mg} / \mathrm{mg}$ at $0-7$ months, $0.6 \mathrm{mg} / \mathrm{mg}$ at $7-18$ months, and $0.42 \mathrm{mg} / \mathrm{mg}$ at 19 months to 6 years; or as a 24-hour urinary calcium excretion of $\leq 4 \mathrm{mg} / \mathrm{kg} /$ day in children older than 1 year [19]). His parathyroid hormone was $25.20 \mathrm{pg} / \mathrm{ml}$ (normal value: $12-88 \mathrm{pg} / \mathrm{ml}$ ) and 25-hydroxy vitamin D was $65.9 \mathrm{nmol} / \mathrm{l}$ (reference ranges: deficiency, $<25$ $\mathrm{nmol} / \mathrm{l}$; insufficiency, $25-74 \mathrm{nmol} / \mathrm{l}$; sufficiency, $75-250 \mathrm{nmol} / \mathrm{l}$; latent intoxication, $>250 \mathrm{nmol} / \mathrm{l})$. Ultrasonography of the urinary system revealed suspected nephrolithiasis (up to $7 \mathrm{~mm}$ in diameter) in both kidneys and urethral calculus (6 $\mathrm{mm}$ in diameter). The infant underwent a cystoscope examination, which alleviated his dysuria by pushing the urethral calculus back into the bladder. Whereafter, the patient was transferred to the Peking University People's Hospital where an abdomen CT demonstrated his bilateral renal calculi, multiple bladder stones and upper ureteral calculi (fig. 1a-c). Under general anesthesia, the patient successively received percutaneous nephrostolithotomy of right kidney, combined with bladder lithotripsy, and of left kidney, respectively. Subsequent analysis revealed the predominant component of renal calcium stones from the operation as calcium oxalate monohydrate and calcium oxalate dihydrate. At the age of 27 months, this family visited our Department of Nephrology to make a definite diagnosis. Clinical characters of the proband including early onset of nephrolithiasis, abnormal increase in urinary excretion levels of oxalate (24-hour oxalate: $1.97 \mathrm{mmol} / 1.73 \mathrm{~m}^{2}$, normal: $<0.46 \mathrm{mmol} / 1.73 \mathrm{~m}^{2}$ ) and calcium (urine $\mathrm{Ca} / \mathrm{Cr}$ ratio: 0.45 ) and decreased level of citrate (24-hour citrate: $329.90 \mathrm{mg} / 1.73 \mathrm{~m}^{2}$, normal: $320-1,240 \mathrm{mg} / 1.73 \mathrm{~m}^{2}$ ) suggested the diagnosis of $\mathrm{PH}$. His renal function was normal $\left(\mathrm{GFR}=149.7 \mathrm{ml} / \mathrm{min} / 1.73 \mathrm{~m}^{2}\right.$, estimated by Schwartz equation $(\mathrm{GFR}=0.41 \times$ height $(\mathrm{in} \mathrm{cm}) /$ 
Table 1. PCR primers for directed sequencing analysis of HOGA1

\begin{tabular}{llll}
\hline Exon & Forward primer $\left(5^{\prime}-3^{\prime}\right)$ & Reverse primer $\left(5^{\prime}-3^{\prime}\right)$ & Product, bp \\
\hline 1 & CCTGACCCTGGGAACACC & CTGCCTGTCTCCTGACTCCA & 551 \\
2,3 & TGGTTGAGCCACTGCATCCCA & TGGCAGTCCACCCGTTTCCTAT & 777 \\
4,5 & CCTGTGGGTGGGCAAGTCT & CCATCCTCCTTCAGCCAACAA & 774 \\
6 & TTTGATGTAGCCAGCCAAGTGA & CAGTGGTGCTCGACTTTGTCC & 461 \\
7 & CCCTGGGTGCCATAGAGTTGG & TCTCCGCTTCAGGCTGCAAGT & 365 \\
\hline
\end{tabular}

Table 2. PCR primers for directed sequencing analysis of GRHPR

\begin{tabular}{llll}
\hline Exon & Forward primer $\left(5^{\prime}-3^{\prime}\right)$ & Reverse primer $\left(5^{\prime}-3^{\prime}\right)$ & Product, bp \\
\hline 1 & GCTTCTGTACTGCCAGGTCC & CCAGAGAACTTTCTCCGAG & 257 \\
2 & CATCAGAGGCCAGGATTCCCAG & GTATCGCAGGAAACGCCCTCAG & 338 \\
3 & CAATAATAAGCGGTGTCCCCATG & GAATGGCCGAGGGATATGCAG & 267 \\
4 & GGAAATGTCCCAGCAGTAGAC & CTCGAACTCCTAACCTCATGATC & 283 \\
5 & GTTTATACCTTGGACCACAGTCA & CATGTGGGTCTTCTCAGCCTTC & 282 \\
6 & TGGCCAGAAATGCTGGGTGGTGTC & GCCACCATTGAGAGAAAATACAGCC & 253 \\
7 & GAGTTTCTGTTAGGGAGTCGG & CTCCAGATGGCAGCAGTG & 301 \\
8 & GTAGGTTGTTCTGCCTCAAAGGT & CTCACACTAGCTCCACACCCG & 302 \\
9 & GTGAAGGTGGGAGAGAAGGCAA & TGTCTGACAATACCAGGGCACG & 327 \\
\hline
\end{tabular}

SCr)). To confirm the diagnosis, genetic analysis was performed on the patient; his family members and healthy controls gave informed consent. The study protocol was approved by the Ethics Committee on Human Studies at the Affiliated Hospital of Qingdao University.

\section{Mutation Analysis}

Genomic DNA was extracted from the peripheral blood of the patients and their family members by GenElute blood genomic DNA kit (Sigma, NA2010). Five and 9 pairs of oligonucleotide primers were generated to amplify all exons and flanking intronic regions of the HOGA1 and GRHPR genes, respectively (tables 1, $2)$. The primer sequences of $A G X T$ were designed according to previous studies [20]. PCRs were performed in $25 \mu \mathrm{l}$ of solution containing $0.2 \mathrm{mM} \mathrm{dNTP}, 0.03 \mathrm{U} / \mu \mathrm{l}$ Taq polymerase (Takara EX Taq Hot start version, DRR006B), $2.0 \mathrm{mM} \mathrm{MgCl}$, $2.5 \mu \mathrm{l} 10 \times$ PCR $\mathrm{Mg}^{2+}$-free Buffer (Takara), approximately $30 \mathrm{ng}$ genomic DNA and $1 \mathrm{mM}$ of each primer. Gradient PCRs were performed with an initial denaturation step at $95^{\circ} \mathrm{C}$ for $5 \mathrm{~min}$, subsequently followed by 33 cycles with denaturation at $95^{\circ} \mathrm{C}$ for $45 \mathrm{~s}$, annealing at 56$66^{\circ} \mathrm{C}$ for $45 \mathrm{~s}$ and elongation at $72^{\circ} \mathrm{C}$ for $45 \mathrm{~s}$. PCR samples were subjected to bidirectional sequencing. The sequence reactions were run on an ABI Prism 3700 DNA Analyzer (Applied Biosystems, Calif., USA).

Minigene Constructions and Expression

To confirm the probable splice mutation affecting an intronexon junction site, in vitro analysis was performed using a minigene splicing assay based on the pSPL3 exon trapping vector [21]. Fragments with the wild or mutant alleles containing the exon of interest, flanked by upstream intronic sequence and downstream intronic sequence, were cloned into the splicing vector PSPL3 using specific primers linking the XhoI and NheI restriction enzyme sites (TGGAGC^^TCGAG: XhoI; AATTTG^CTAGC: NheI). The ancestral and mutant type constructs were named pSPL3-W and pSPL3-M, respectively. All constructs were verified to contain the correct sequence by direct sequencing.

Human Embryonic Kidney $293 \mathrm{~T}$ cells were cultured in DMEM medium containing $10 \%$ FBS, $1 \%$ penicillin-streptomycin (Invitrogen, Calif., USA) at $37^{\circ} \mathrm{C}$ in a $5 \% \mathrm{CO}_{2}$ atmosphere. One day before transfection, cells were transferred to 6-well culture plate to grow to approximately $70-80 \%$ confluence in an antibiotic free medium. Cells were then transfected with $4 \mu \mathrm{g}$ plasmid DNA (pSPL3-W, pSPL3-M and empty pSPL3-control each) using Lipofectamine 2000 (Invitrogen, Calif., USA), according to the manufacturer's instructions. Cells were harvested, total RNA was extracted from the Human Embryonic Kidney 293 T cells after $48 \mathrm{~h}$ of transfection using TRIzol reagent (Invitrogen, Calif., USA) and used for RT-PCR to confirm the splicing patterns. First-strand cDNA was synthesized from $1 \mu \mathrm{g}$ of total RNA by random-primed reverse transcription using PrimeScript 1st Strand cDNA Synthesis Kit (TaKaRa, Japan). To evaluate the pattern of transcripts from the transfected minigenes, the following vector-specific primers were used for RT-PCR amplification: a forward primer SD6 (5'-TCTGAGTCACCTGGACAACC- $\left.3^{\prime}\right)$ and a reverse primer SA2 $\left(5^{\prime}\right.$-ATCTCAGTGGTATTTGTGAGC$\left.3^{\prime}\right)$. The PCR amplification reaction was performed as follows: in $50 \mu$ l volume, $2 \mu \mathrm{l}$ of cDNA, $10 \mu \mathrm{l}$ of $5 \times$ PrimerSTAR Buffer (TaKaRa, Japan), $1 \mu \mathrm{M}$ of each primer, $0.8 \mu \mathrm{M}$ dNTPs and $0.5 \mathrm{ul}$ PrimerSTAR HS DNA Polymerase (TaKaRa, Japan) in a 9700 (Applied Biosystem, Calif., USA) thermal cycler. Thermal conditions were 29 cycles of $98^{\circ} \mathrm{C}$ for $15 \mathrm{~s}, 58^{\circ} \mathrm{C}$ for $15 \mathrm{~s}$ and $72^{\circ} \mathrm{C}$ for $50 \mathrm{~s}$, fol-
80
Am J Nephrol 2015;42:78-84 DOI: $10.1159 / 000439232$
Wang/Zhao/Wang/Yao/Zhang/Lang/ Tuffery-Giraud/Bottillo/Shao 


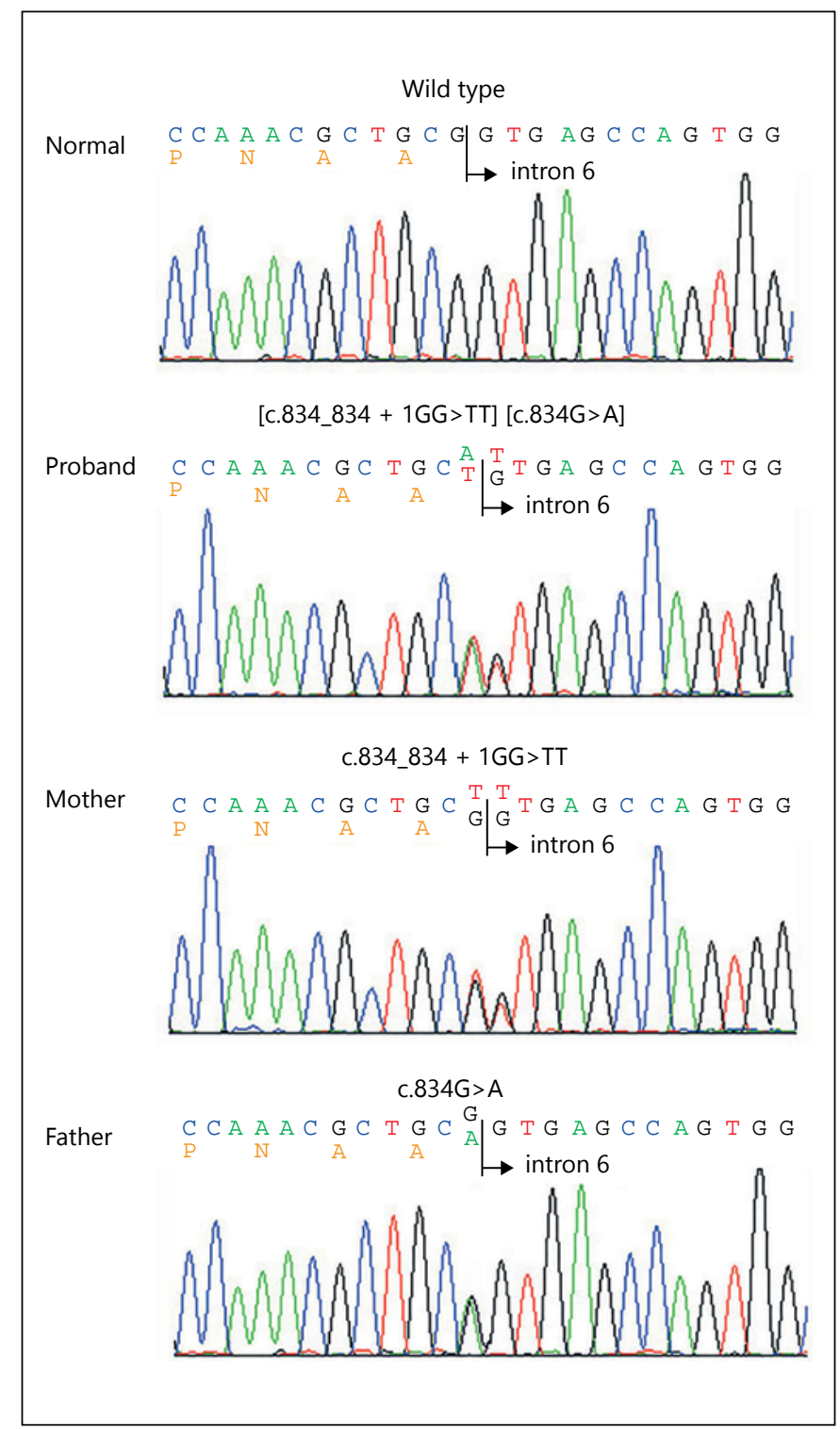

Fig. 2. HOGA1 mutations identified in this Chinese family with $\mathrm{PH} 3$.

lowed by a final elongation step at $72^{\circ} \mathrm{C}$ for $10 \mathrm{~min}$. The PCR products were separated by electrophoresis on a $2 \%$ agarose gel, and each band signal was quantified by Quantity One software (Bio-Rad, Richmond, Calif., USA). All transcripts were analyzed by sequencing.

\section{Results}

Mutational analysis in the patient showed compound heterozygosity for mutations in HOGA1 (fig. 2). One mutation was a successive 2-nucleotide substitution at the last position of exon 6 and the first position of intron 6 respectively (c.834_834 + 1GG>TT), including the change of classical donor splicing site (GT $\rightarrow \mathrm{TT}$ ) combined with the alteration of its upstream close neighbor nucleotide, both sites may play an important role as splicing modulator. The BDGP splice prediction program (available at http://www.fruitfly.org/seq_tools/splice.html) was employed to test whether this mutation altered the splicing of the HOGA1 transcript. That prediction resulted in the abolishment of the donor splice site (score cutoff 0.40 ). The second variant found in the patient was a guanine to adenine substitution of the last nucleotide of exon 6 (c.834G $>$ A), which result in a synonymous mutation (p.Ala278Ala). However, this variant may also affect canonical splice donor nucleotide positioning by BDGP in silico analysis (the score decreases from 0.86 to 0.24 ). We inferred the haplotype's phase by analyzing the parents DNA. We found that the father carried the heterozygous c. $834 \mathrm{G}>\mathrm{A}$ variant, while the mother carried the heterozygous c.834_834 + 1GG>TT mutation. In addition, we found in the patient a missense mutation (c.715G $>A$, p.V239I) inherited from his father. PolyPhen-2 (available at http://genetics.bwh.arvard.edu/pph2) analysis predicted that this variant is 'benign'. This mutation is also listed in the NCBI dbSNP database. No mutation was detected in $A G X T$ and GRHPR. Both the heterozygous c. $834 \mathrm{G}>\mathrm{A}$ and c.834_834 + 1GG $>$ TT mutations were absent in 200 normal chromosomes, while the p.V239I was found in heterozygosity in 6 ones ( 6 of 200). So p.V239I is unlikely to be a disease-causing mutation, and it is more likely a benign SNP.

To define effects of these 2 novel variants at the transcript level, we performed minigene studies using the pSPL3 plasmids. According to the above description, in 'Methods', the fragments with the wild or mutant alleles involving exon 6 (134 bp), flanked by upstream intronic sequence ( $388 \mathrm{bp}$ ) and downstream intronic sequence ( 438 $\mathrm{bp})$, were cloned into the splicing vector pSPL3 using specific primers (forward, $5^{\prime}$-TTCCCATCCGTCCTACCCT$3^{\prime}$; reverse, $5^{\prime}$-CCTGCCTTCTAACTCCTTTGC-3') linking the XhoI and NheI restriction enzyme sites (fig. 3a). The minigene assays showed that both the empty pSPL3 control and c.834_834 + 1GG>TT mutant constructs gave rise to a $263 \mathrm{bp}$ PCR fragment missing exon 6 of HOGA1 gene, while the wild-type gave rise a $397 \mathrm{bp} \mathrm{PCR} \mathrm{product}$ containing exon 6 . However, the c.834G $>$ A mutant construct yielded 2 lengths of RT-PCR products corresponding to 263 and $397 \mathrm{bp}$ PCR fragments, respectively (the gradation ratio of 2 bands is about $2: 1$ ), which was determined by sequencing analysis (fig. $3 b$ ). 


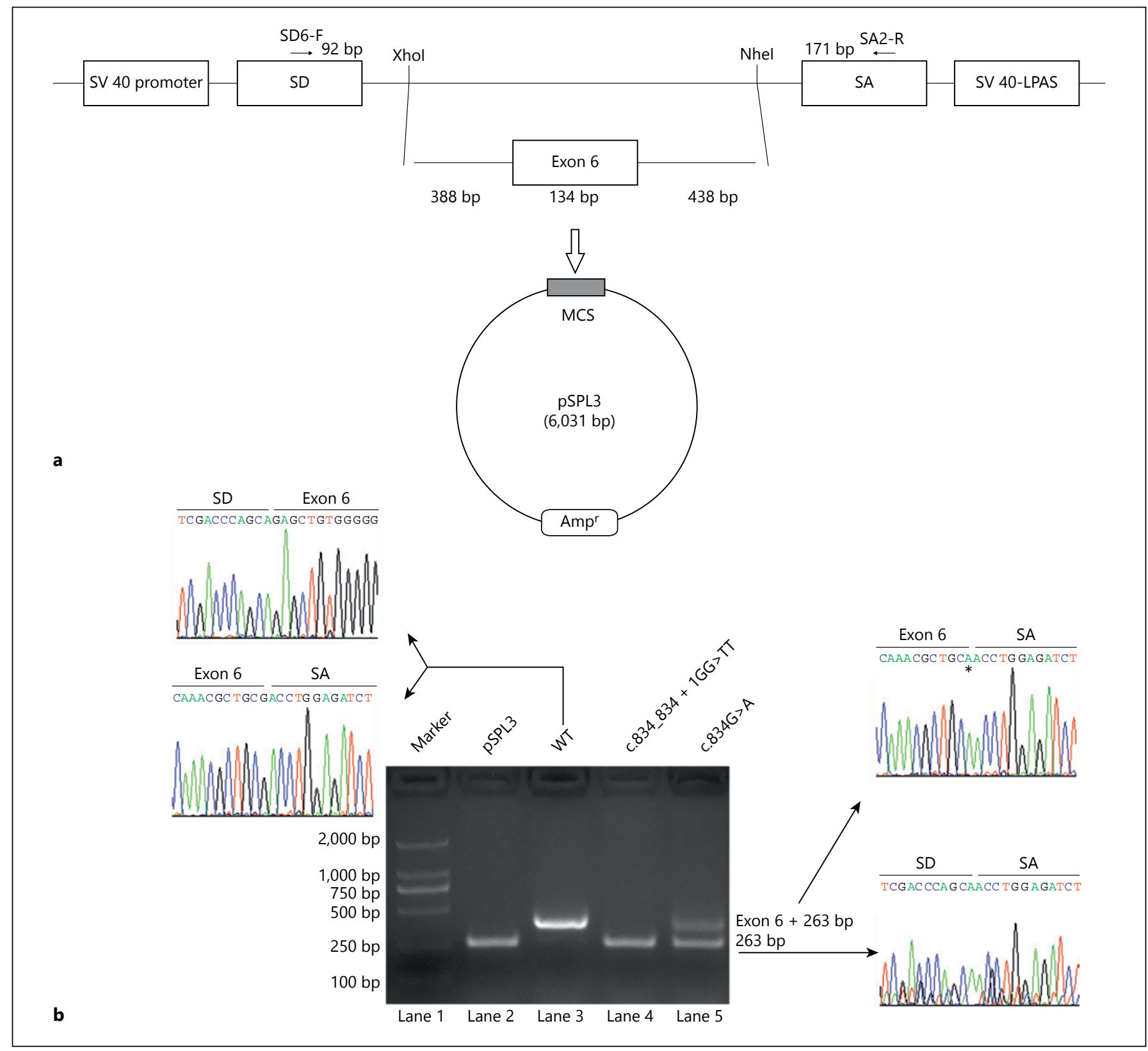

Fig. 3. The minigene splicing assay based on the PSPL3 exon trapping vector. a The pSPL3 vector contains 2 exons SD and SA, and a functional intron, with transcription beginning following the SV40 promoter and ending at the LPAS. Wild pSPL3-W and mutant pSPL3-M plasmids containing 388 bp of intron 5, 134 bp of exon 6 and $438 \mathrm{bp}$ of intron 6 were separately cloned into the XhoI and

\section{Discussion}

The molecular mechanisms of $\mathrm{PH} 1$ and $\mathrm{PH} 2$ were identified in 1988 and 1999, respectively [7, 10]. However, the association of $\mathrm{PH} 3$ and mutations in HOGA1 gene
NheI cloning sites of the pSPL3 vector. b Agarose gel electrophoresis of RT-PCR products. SD6 and SA2 primers were designed for RT-PCR amplification of cDNA sequences generated by transfected 293 T cells. Lane 1: marker; Lane 2: empty vector (263 bp); Lane 3: $397 \mathrm{bp}(263+134 \mathrm{bp})$; Lane 4: $263 \mathrm{bp}$; Lane 5: 263 and $397 \mathrm{bp}(263 \mathrm{r}+$ $134 \mathrm{bp})$. MCS $=$ Multiple cloning sites; LPAS = late poly(A) signal.
82

Am J Nephrol 2015;42:78-84 DOI: $10.1159 / 000439232$
Wang/Zhao/Wang/Yao/Zhang/Lang/ Tuffery-Giraud/Bottillo/Shao 
23]. Up to now, all the above-described $\mathrm{PH} 3$ mutations came from the population of European Americans.

Preliminary mutation analysis of HOGA1 gene in this family showed that the proband was a compound heterozygote of 2 different mutations. The minigene splicing assay using the pSPL3 plasmids confirmed c.834_834 + $1 \mathrm{GG}>\mathrm{TT}$ was a spicing mutation causing a complete skipping of exon 6, resulting in a frame shift from codon 235 and premature termination at position 268 in exon 7. Interestingly, the mutation c.834G $>$ A led to the expression of 2 transcripts of which the majority of splice product was missing exon 6 , the minority was not. These results demonstrated that the last nucleotide (c.834G) of exon 6 in HOGA 1 gene was also an important controller of splicing, and the change of guanine to adenine at this position led to a significant decrease in the ability of splice site (donor site) recognition. However, we have to point out the limitation of this study in which only a small part of DNA fragment flanking exon 6 was cloned and analyzed in vitro compared with the large fragment with a 9520-bp intron 6. Therefore, we cannot exclude the probability of multiple exons skipping or activation of a cryptic splice site in deep intron 6 not investigated in this study under the circumstance of having a weaker splice site due to the mutation c. $834 \mathrm{G}>\mathrm{A}$. Unfortunately, it was not possible to analyze the patient's RNA for confirming the in vitro results because we cannot obtain it. In spite of this, we have enough convincing reasons to think of c. $834 \mathrm{G}>\mathrm{A}$ as a virtual splicing mutation. Meanwhile, we should notice that the partial effect of mutation c.834G $>$ A on splicing might lead to a mixed population of transcripts with the abnormal splicing and normal full length transcripts, which gives rise to a normal protein because the $c .834 \mathrm{G}>\mathrm{A}$ mutation is a synonymous mutation (p.Ala278Ala) in vivo, as seen in our study. Therefore, there may be some residual HOGA activity in the body of this patient, although the possibility is small. This study expanded the spectrum of mutations in the HOGA1 gene associated with $\mathrm{PH} 3$ from 26 to 28 ones.

The association of clinical and biochemical characteristics, as well as the results of molecular analysis, suggested the diagnosis of $\mathrm{PH} 3$ in this case. However, the proband presented higher levels of urinary oxalate and lower urinary citrate, compared with the most previously described $\mathrm{PH} 3$ patients. This discrepancy may be associated with a more severe phenotype (with 2 splicing mutations) in this patient. And that, in turn, may suggest c. $834 \mathrm{G}>\mathrm{A}$ is also a severe splicing mutation. Hence, the evolution and prognosis of the patient deserve close follow-up.

Two Novel Splice Site Mutations in HOGA1
According to the very recent study by Hopp et al. [17], the overall carrier frequency of $\mathrm{PH}$ is approximately $1: 70$, and the inferred prevalence is approximately 1:58,000. Surprisingly, the carrier frequency of $\mathrm{PH} 3$ is higher than $\mathrm{PH} 1$; however, $\mathrm{PH} 3$ is 6-fold less common in currently clinical populations. The difference between the expected and observed prevalence for $\mathrm{PH} 3$ may be due to the underdiagnosis of this disease, which has overall milder phenotypes and is much less likely than PH1 to result in ESRD [17]. Additionally, Monico et al. [18] found that some HOGA 1 carriers present with mild hyperoxaluria or idiopathic urinary stone disease, they suppose this may be related to haploinsufficiency. Therefore, HOGA1 gene analysis of idiopathic calcium oxalate urolithiasis populations and other patients with $\mathrm{PH}$ phenocopies, but no known mutations, is likely to be informative regarding undiagnosed $\mathrm{PH} 3$ cases.

In summary, we identified 2 splicing mutations of HOGA1 gene in a Chinese patient with $\mathrm{PH} 3$. This is the first report of a $\mathrm{PH} 3$ patient among Asians. Further investigations in this population, especially cases with $\mathrm{PH}$ phenocopies, such as unexplained hyperoxaluria, early onset of nephrolithiasis or nephrocalcinosis and familial urolithiasis, are highly needed.

\section{Acknowledgments}

This study was supported by grants from the National Natural Scientific Foundation (81170653 \& 81202314).

\section{Disclosure Statement}

The authors have declared that no competing interests exist.

References

1 Hoppe B, Beck BB, Milliner DS: The primary hyperoxalurias. Kidney Int 2009;75:1264-1271.

2 Harambat J, Fargue S, Bacchetta J, Acquaviva C, Cochat P: Primary hyperoxaluria. Int J Nephrol 2011;2011:864580.

3 Cochat P, Liutkus A, Fargue S, Basmaison O, Ranchin B, Rolland MO: Primary hyperoxaluria type 1: still challenging! Pediatr Nephrol 2006;21:1075-1081.

4 Hoppe B, Langman CB: A United States survey on diagnosis, treatment, and outcome of primary hyperoxaluria. Pediatr Nephrol 2003;18:986-991.

5 Herrmann G, Krieg T, Weber M, Sidhu H, Hoppe B: Unusual painful sclerotic plaques on the legs of a patient with late diagnosis of primary hyperoxaluria type I. Br J Dermatol 2004;151:1104-1107. 
6 Archer HE, Dormer AE, Scowen EF, Watts RW: Primary hyperoxaluria. Lancet 1957;273: 320-322.

7 Danpure CJ, Jennings PR: Peroxisomal alanine: glyoxylate aminotransferase deficiency in primary hyperoxaluria type I. FEBS Lett 1986;201:20-24.

8 Kamoun A, Lakhoua R: End-stage renal disease of the Tunisian child: epidemiology, etiologies, and outcome. Pediatr Nephrol 1996; 10:479-482.

9 Al-Eisa AA, Samham M, Naseef M: End-stage renal disease in Kuwaiti children: an 8-year experience. Transplant Proc 2004;36:17881791.

10 Cramer SD, Ferree PM, Lin K, Milliner DS, Holmes RP: The gene encoding hydroxypyruvate reductase (GRHPR) is mutated in patients with primary hyperoxaluria type II. Hum Mol Genet 1999;8:2063-2069.

11 Hoppe B: An update on primary hyperoxaluria. Nat Rev Nephrol 2012;8:467-475.

12 Cochat P, Rumsby G: Primary hyperoxaluria. N Engl J Med 2013;369:649-658.

13 Belostotsky R, Seboun E, Idelson GH, Milliner DS, Becker-Cohen R, Rinat C, Monico CG, Feinstein S, Ben-Shalom E, Magen D, Weissman I, Charon C, Frishberg Y: Mutations in DHDPSL are responsible for primary hyperoxaluria type III. Am J Hum Genet 2010;87:392-399.
14 Riedel TJ, Knight J, Murray MS, Milliner DS, Holmes RP, Lowther WT: 4-Hydroxy-2-oxoglutarate aldolase inactivity in primary hyperoxaluria type 3 and glyoxylate reductase inhibition. Biochim Biophys Acta 2012;1822: 1544-1552.

15 Williams EL, Bockenhauer D, van't Hoff WG, Johri N, Laing C, Sinha MD, Unwin R, Viljoen A, Rumsby G: The enzyme 4-hydroxy2-oxoglutarate aldolase is deficient in primary hyperoxaluria type 3. Nephrol Dial Transplant 2012;27:3191-3195.

16 Beck BB, Baasner A, Buescher A, Habbig S, Reintjes N, Kemper MJ, Sikora P, Mache C, Pohl M, Stahl M, Toenshoff B, Pape L, Fehrenbach $\mathrm{H}$, Jacob DE, Grohe B, Wolf MT, Nürnberg G, Yigit G, Salido EC, Hoppe B: Novel findings in patients with primary hyperoxaluria type III and implications for advanced molecular testing strategies. Eur J Hum Genet 2013;21:162-172.

17 Hopp K, Cogal AG, Bergstralh EJ, Seide BM, Olson JB, Meek AM, Lieske JC, Milliner DS, Harris PC; on behalf of the Rare Kidney Stone Consortium: Phenotype-genotype correlations and estimated carrier frequencies of primary hyperoxaluria. J Am Soc Nephrol 2015;pii:JASN.2014070698.

18 Monico CG, Rossetti S, Belostotsky R, Cogal AG, Herges RM, Seide BM, Olson JB, Bergstrahl EJ, Williams HJ, Haley WE, Frishberg
Y, Milliner DS: Primary hyperoxaluria type III gene HOGA1 (formerly DHDPSL) as a possible risk factor for idiopathic calcium oxalate urolithiasis. Clin J Am Soc Nephrol 2011;6:2289-2295.

19 Sargent JD, Stukel TA, Kresel J, Klein RZ: Normal values for random urinary calcium to creatinine ratios in infancy. J Pediatr 1993; 123:393-397.

20 Monico CG, Rossetti S, Schwanz HA, Olson JB, Lundquist PA, Dawson DB, Harris PC, Milliner DS: Comprehensive mutation screening in 55 probands with type 1 primary hyperoxaluria shows feasibility of a gene-based diagnosis. J Am Soc Nephrol 2007;18:1905-1914.

21 Bottillo I, De Luca A, Schirinzi A, Guida V, Torrente I, Calvieri S, Gervasini C, Larizza L, Pizzuti A, Dallapiccola B: Functional analysis of splicing mutations in exon 7 of NF1 gene. BMC Med Genet 2007;8:4

22 Pitt JJ, Willis F, Tzanakos N, Belostotsky R, Frishberg Y: 4-Hydroxyglutamate is a biomarker for primary hyperoxaluria type 3 . JIMD Rep 2015;15:1-6.

23 Allard L, Cochat P, Leclerc AL, Cachat F, Fichtner C, De Souza VC, Garcia CD, Camoin-Schweitzer MC, Macher MA, Acquaviva-Bourdain C, Bacchetta J: Renal function can be impaired in children with primary hyperoxaluria type 3. Pediatr Nephrol 2015, Epub ahead of print. 